33 per cent loss of grown herbage in the process of grazing and conservation. This is done by strip grazing for limited periods and housing the cows at night. Each field is cut or grazed five or six times per season, nitrogenous fertilizer being applied following each cut or grazing period. By alternating cutting and grazing, palatability is improved. Dung is only applied to fields the crops of which are to be cut for silage the following season. The yield of cows shows that grass grown in September or October is not so productive of milk as that grown earlier in the summer. Starchy foods are used to balance the grass and give better utilization.

The second session of the meeting was devoted to the "Agronomic and Physiological Considerations governing Grassland Utilization". For this subject the principal paper was in two parts, the first on the physiological aspects being given by A. M. Frens, of The Netherlands State Agricultural Experiment Station at Hoorn, while the second, on the economic principles of grassland farming, was given by $\mathrm{H}$. Dijkstra, of The Netherlands Agricultural Economics Research Institute.

Mr. Frens, in a clear and persuasive paper, pointed out the difficulties with which cattle on intensively managed pasture have to contend in dealing with the physical structure and high moisture content of young tender grass on which they are expected to live for long periods. Where the feed is low in fibrous and stemmy components, it tends to pack too closely in the rumen, and optimal microbial activity does not develop. This may lead in extreme cases to a deficiency of those nutrients of microbial origin which are essential to the animal's well-being. Not only so, but also the large quantities of water that have to be dealt with by animals living on luscious young grass strain their resorptive capacity, and water resorption from the intestines may be less effective than it physiologically should be. This results in soft fæces, in which an excess of minerals is excreted. Cattle which are scouring, moreover, tend to have a greater sodium and copper requirement, and the grass may contain insufficient to meet the extra demand caused by the increased loss by excretion. Supplementary food to give additional fibre to cattle on highly stimulated pastures can be an advantage, even if the grass contains all the nutrients needed for the animal's level of production. It should be chosen carefully, so that it does not prevent a high intake of grass, and the inclusion of extra sodium, copper and perhaps magnesium may be worth while.

Mr. Dijkstra's paper was the only one dealing with economic aspects. He laid down three conditions that must be fulfilled for the most economical production: (a) grass and grass products must be adapted, in the most economical way and along with any purchased feeding-stuffs, to the feeding require. ments of the farm livestock ; $(b)$ the farm equipment, soeds, fertilizers and labour used must be so applied that no greater net output could be obtained by utilizing them in any other line of production; and (c) the primary products of the enterprise (grassland products) must be converted as efficiently as possible into the secondary products (milk, meat, etc.). These three conditions are not independent of each other, but have a mutual influence.

There were twelve subsidiary papers in this session, of which two were contributed from the United Kingdom. W. F. Raymond, of the Grassland Research Station, reviewed the problems involved in the "Estimation of Herbage consumed by Grazing
Stock". At the Grassland Research Station, as in New Zealand, the fæcal index method is being developed. It is felt that this method is likely to give greater accuracy than others being tried in America; and that from it an estimate of the grazing intake can be made and a measure of the herbage quality obtained. While the technique is simple to operate, it is dependent on adequate sampling, and to this greater attention has still to be given. J. L. Corbett, of the Rowett Research Institute, dealt with "Some Aspects of the Nutrition of Grazing Dairy Cows" and gave details of trials in which the effects of supplementary foods on herbage intake were studied.

Other contributions were from France, Portugal, Switzerland, Belgium, Germany, The Netherlands, Finland and Italy. Dr. L. Seekles, of The Netherlands, dealt with grass or lactation tetany, to which he prefers to give the name 'nutrition tetany'. He criticized the suggestion frequently made that intensively fertilized pasture is a prime cause, since it may occur both on lush pastures and in stall-fed cattle. In addition to the visible symptoms of tetany, there is also gastro-intestinal disfunction. It is possible that certain poisons of intestinal origin interfere with the magnesium-regulating centre in the brain, causing a shift of magnesium from the blood to the tissues. This may be initiated by abnormal functioning of the digestive tract due to its overburdening with excessive food, whether it be lush pasture or other foods. More than one contributor directed attention to the importance of developing the correct bacterial flora for the best digestive utilization of silage. Invariably, animals to which silage is introduced make little or no progress for some time, though later they may recover the lost ground. This appears to be due to the time taken for the correct bacteria for digestion of silage to develop. Further study of this aspect of digestion and of the best utilization of various forages is needed.

A characteristic of both sessions was the vigorous discussion, which was ably directed by the president, Prof. A. M. Leroy. The meeting concluded with the adoption of a resolution calling for intensified research on international lines on the problems of producing a high yield of good-quality grass and of its utilization. There is still, except in some circumstances, a failure to use the full potentiality of the grass crop.

A. R. WANNOP

\section{INSTITUTE OF MEDICAL LABORATORY TECHNOLOGY}

\section{SEVENTH TRIENNIAL CONFERENCE}

$\mathrm{T}$

HE seventh triennial conference of the Institute of Medical Laboratory Technology was held in the University of Nottingham during August 29September 2. In opening the conference, Dr. G. E. Godber, joint deputy chief medical officer to the Ministry of Health, spoke on the development of the pathology services in Great Britain. $\mathrm{He}$ began, appropriately, by showing the build-up of laboratory services in the North Midland Region since the beginning of the Second World War, during which the Emergency Pathology Service became the forerunner of the existing network. In spite of war-time improvements, the pathological services over the whole country were far short of requirements when the National Health Service took over in 1948. 
Between then and 1954 the amount of pathological work has doubled; almost two thousand technicians and about the same number of student technicians were employed last year in National Health Service laboratories. This increase of laboratory work should be looked upon as part of a process established before the Health Service or even before the War. We have moved from the conception of a hospital which was primarily to provide beds in which patients recovered with varying degrees of assistance from their attendants, to one in which the hospital is a diagnostic and treatment centre, where most patients are out-patients, their needs being met without admission. Admission to the ward is now regarded as a stage in the patient's life and illness which should in his own interests be cut as short as is compatible with speedy and effective cure. Briefly, the hospital is a special kind of service which stands behind, and supports, the great bulk of curative work that is done in other places - surgeries, clinics and the patients' own homes.

Naturally, the bulk of the most complex and highly scientific work is done for patients attending consultative out-patient departmonts or admitted to the wards. This should not hide the importance of the laboratory's share in diagnosis and treatment in other places, and it is necessary that this side of its work should be expanded. The work of general practitioners is of great importance because so much of it can lead to earlier diagnosis, prevention of serious illness, and the reduction of the load on other departments of the hospital. There is ample evidence that the availability of the pathology laboratory to the general practitioner does not swamp the laboratory with work at the expense of the requirements of the hospital itself : it may even have the opposite effect. That every practitioner should be able to refor his cases direct to the laboratory is a prime necessity.

Speaking of the capital development plan for hospitals, Dr. Godber said that it is commonly believed that a now hospital must necessarily cost more to run than an old one, and it may be that a new one will cost more per bed per year; but if the now hospital makes it possible to treat three patients in the number of bed-days formerly required for two, then there is a margin for increasing cost per patientday and still reducing the cost per patient treated. A modern pathological service can do much to enhance this process, and particular care is needed in hospital planning to ensure that such departments as pathology and radiology are on a sufficient scale to meet all requirements efficiently and at the same time with economy in man-power.

The laboratory, continued Dr. Godber, is part of the hospital and should not be divorced from it; the clinician relies upon laboratory workers for accurate and expert information which gives him the assurance that enables him to control the complicated armamentarium of treatments. Diagnosis is, after all, rarely a simple process of exact definition and needs a balance of evidence from a variety of sources. Likewiso, modern troatmonts often need the most exacting control, and for these reasons there needs to be close contact between the laboratory and the clinician. Along with the use of more complicated and more accirate apparatus, there has been an increasing devolution of responsibility to the technical staffs of medical laboratories. The Institute of Medical Laboratory Technology has played a great part in facilitating the changes which have taken place in the past few years by its promotion of education and its qualifying examinations and by maintaining and achieving a status for the medical laboratory technician which is now recognized in Britain throughout the national hospital service and all other laboratories.

There were five sessions of scientific loctures at the conference, about two-thirds of which were given by Institute members and the remainder by guest speakers. Dr. M. Lumb spoke on the influence of antibiotics on modern clinical bacteriology; the influence of these substances in the treatment and bacteriology of tuberculosis occupied part of the talk given by Prof. Robert Cruickshank, president of the Institute. Some of the most interesting of the recent problems in this disease have been raised by the type of lesion in which the tubercle bacillus can be demonstrated microscopically but not culturally. Prof. Cruickshank ended his observations with a very necessary warning to laboratory workers. Many laboratories are now handling tuberculous material, and the need for antibiotic control has resulted in a great increase of living culture work. The incidence of the disease in laboratory workers is disturbing, and every possible care should be taken to guard against laboratory infection.

Prof. E. J. W. Barrington, of the Department of Zoology in the University of Nottingham, was able to show a common meoting-ground for those who work in pathology departments and those who work in other specialties, when he spoke of the place of histology in endocrinological research. Certain of the new cytochemical methods, he said, are of equal value in the earthworm and in man. Mr. F. A. Ibbott gave a provocative paper on the error induced in volumetric glasswaro by drying and sterilization with heat ; his own experiments, some of them drastic, have shown that no significant changes were produced by dry heat in certain of his own standard apparatus. Dr. J. C. White, of the Postgraduate Medical School of London, gathered together recent advances in our knowledge of the human hæmo. globins, while Dr. N. P. Burman dealt with methods of detecting and counting antagonistic micro-organisms in soil and described some of his own methods for simplifying a tedious and time-consuming process.

Prof. K. E. Cooper, professor of bacteriology in the University of Bristol, took modern trends in microscopy as his subject and illustrated the principles of phase-contrast, electron and interference microscopy. Speaking of ordinary microscopy, Prof. Cooper deplored the tendency of some workers to set up a very good microscope with a poor illuminating system, so not making full use of their instrument. Mr. J. S. Simpson showed methods employed in the microbiological assay of antibiotics, vitamins and amino-acids, and was able to demonstrate how the use of large sandwiches of agar between glass plates saves the use of considerable quantities of Petri dishes. Dr. G. R. Osborn, director of pathology, Derbyshire Royal Infirmary, gave many examples of the use of modern eytological techniques in the early diagnosis of cancer, and he was followed by Miss M. E. Attwood, who has applied such techniques to the problem of diagnosing uterine carcinoma in particular.

Among other papers were those of Miss V. A. L. Brews, who dealt with electrophoretic patterns of blood sera and the flocculation tests, while Miss E. L. Bown gave a résumé of semi-micro methods used in pædiatric biochemistry. Dr. H. M. Rice, director of pathology, General Hospital, Nottingham, made 
observations on the sensitivity of the hæmolytic system in complement fixation tests and showed the greater reliability of modern modifications in the tests, for example, for syphilis. Mr. I. Dunsford, of the Sheffield Blood Transfusion Service, was able to draw on an extensive practical experience in discussing the difficulties encountered when selecting suitable blood for transfusion purposes. His main point was that no one test should be relied upon when cross-matching blood but that saline and albumin techniques should always be employed, with the addition of the Coombs test in cases where there was a risk of the patient having been immunized by previous transfusions or pregnancies.

In addition to these and other papers, numerous demonstrations were on view all the week. For the first time at an Institute conference a large number of foreign laboratory workers were present, and an evening was spent on discussion of matters of common interest. Another innovation was a demonstration for the public who, generally speaking, are not very knowledgeable about what takes place in the hospital laboratory. This demonstration, the result of much co-operation between local pathologists, technicians and many others, was open for only three hours on each of two successive evenings; but the success of the experiment may be judged by the fact that during this short time more than a thousand people visited it.

\section{PRESERVATION OF FOOD BY IONIZING RADIATIONS}

$\mathrm{T}$

HE traditional methods available for the preservation of food are several and varied in their nature. The almost prehistoric method of drying involving the use of solar radiations-unrecognized as such-was the subject of much research some years ago, and this work was very useful to Great Britain during the Second World War when there was a great shortage of shipping space. Some of the chemical preservatives, studied by the 1924 Departmental Committee of the Ministry of Health, often 'blunderbuss' in function, are virtually unused outside the British Isles where those of more recent introduction have been found acceptable both by the industry and the authorities. The availability of antibiotics-some very specific in their action-has created new problems for those who advise our legislators on the desirability of permitting additions to the schedule of preservatives, for such they are. In the realm of food science, experimentation and development, although more sedate in their progress compared with some of the other branches of science, often outstrip the ability of the manufacturers to take advantage of them.

The initial discovery by Röntgen in 1895 that X. rays can damage and destroy living cells has in more recent years been extended over the broader field of ionizing radiations in general. The situation to date, as recorded in various journals mainly of American origin, is that radiations derived from electrical generators, radioactive elements and nuclear reactions are available which exert a lethal effect upon micro-organisms and insects. Parallel with these observations have been reports of reactions initiated by the exposure of food components to such radiations-breakdown of amino-acids, fats, vitamins and so on. The food technologist faced with a new series of units repre- senting the dosage of the product under treatment has often been in difficulty in grasping the significance of the evidence given in these reports and the very long list of journals in which such reports are sometimes hidden only adds to his confusion. With considerable foresight, the Food Investigation Organrzation of the Department of Scientific and Industrial Research, as befits its name, has come to the aid of food technologists in providing, through the efforts of Dr. R. S. Hannan, a wealth of information and, let us not delude ourselves, of instruction in its Special Report No. 61 on "Scientific and Technological Problems involved in using Ionizing Radiations for the Preservation of Food"*. The bibliography of some four hundred odd references in this publication will satisfy every collector of reprints and is alone worth every penny of the modest price.

In his survey, Dr. Hannan deals with the ionizing radiations, their generation, their properties and the technical problems associated with their use. Having described the positive advantages of the use of this modern weapon, he very wisely presents for the reader's consideration the various gaps in our know. ledge which must be filled before we are able to contemplate using it. The most suitable type of radiation and its optimum dose, the possibility of reactions initiated by such dosage involving the production of undesirable and maybe toxic substances or the destruction of some essential constituent-all these will need to be studied in extenso and by teams of workers. We are grateful for the information and for the guidance as to future research, and we look forward to the results of the further researches of Dr. Hannan and his colleagues.

\section{F. H. BANHTELD}

* Department of Scientific and Industrial Research. Food Investigation Special Report No. 61 : Scientiflc and Technological Problems involved in using Ionizing Radiations for the Preservation of Food.
By Dr. R. S. Hannan. Pp. vili +192. (London: H.M.S.o., 1955.) 7s. $6 d$.

\section{PHYSICS OF THE IONOSPHERE}

THE rapid advances being made in many fields of 1 scientific research leads to a vast amount of published literature in which it is not easy for the student and research worker to discover the real milestones of progress. As a means of partly mitigating this difficulty, there is now an established practice of organizing a conference or symposium at which a particular subject or field of investigation is reviewed and discussed, mainly by those working in the subject. Such a conference forms a suitable focus and also acts as a stimulant to those who otherwise may be rather dilatory in describing their own contributions or putting forward well-founded views on the work of others. The results of such a conference are made of immensely greater value when all the papers which were read and discussed are collected together and published in some recognized standard form.

The conference on "The Physics of the Ionosphere", held under the auspices of the Physical Society at the Cavendish Laboratory, Cambridge, in September 1954 (Nature, 174, 866; 1954), meets all these requirements with the publication of the report which is now available*. The report comprises fifty in-

* Physical Society. Report of the Phystcal Society Conference on the Physics of the Ionosphere, held at the Cavendish Laboratory, Society, 1955.) $40 s$. 